\section{Performance after awakening at different times of night*}

\author{
R. T. WILKINSON and M. STRETTON \\ Medical Research Council, Applied Psychology Unit, Cambridge, England
}

Naval ratings were roused during the night and presented themselves, dressed, for testing in a nearby room within $4 \mathrm{~min}$. During the next $11 \mathrm{~min}$, they were given tests of reaction time, calculation, and muscular coordination and steadiness. In all three tests, performance was well below the normal level achieved during the day. On different occasions, the men were roused at different times of night, and this factor influenced which task was affected most. Reaction time, with its intermittent call for rapid response, was impaired most in the early part of the night; the adding and coordination tasks, which demanded more continuous performance, were more affected later in the night. It is suggested that the early effects may be due to the depth of the preceding sleep, while the later ones may be influenced more by the trough in the circadian cycle of physiological activity.

Over the last 10 years, there have been at least seven studies carried out with the aim of assessing performance soon after sudden awakening. In a series of experiments dating from 1961 (Hartmann \& Langdon, 1961, 1965; Hartmann, Langdon, \& McKenzie, 1965), Ss were tested for $10 \mathrm{~min}$, commencing some $2 \mathrm{~min}$ after awakening either at the usual time in the morning, at midnight, or at $0300 \mathrm{~h}$. Performance was worse than when the same tasks were carried out just before retiring at $2230 \mathrm{~h}$. There were, however, no significant differences between the three times of awakening. Two tests were given: response time to the onset or offset of displays in a complex behavior simulator, and a multidimensional pursuit test. In general, the effect of sudden awakening was the same for both tasks. Jeannaret \& Webb (1963), who carried out the next study in this field, restricted their examination to performance following waking at the usual time in the morning, at which time they asked their Ss to stand up and squeeze a dynamometer three times. Grip strength was $13 \%$ less than when tested during normal wakefulness in the early afternoon. In a further experiment from the same laboratory, two modifications in the technique were introduced: Ss were tested in bed to make the performance follow "immediately upon awakening" (Agnew, Webb, \& Williams, 1964), and, second; the arousal from sleep was carried out in the afternoon; the control comparisons were with the same routine of tests carried out before and after the midday meal and 5 min after arousal. The test was one

* Experimental Ss were supplied by the Royal Navy (U.K.), and the work forms part of a program of research for the Royal Naval Personnel Research Committee. of pressing four numbered switches in the order of four numbers on a display panel. Time was taken to the first response and for the whole sequence. Five trials were run in the $60 \mathrm{sec}$ following awakening. Performance in all five trials was well below normal and that of the first trial particularly so.

Although the EEG was recorded in the study of Agnew, Webb, \& Williams (1964) (to achieve arousal from the Stage 4 EEG record where possible), no attempt was made to analyze results as a function of the stage of sleep from which Ss were aroused. There exists, however, a brief report of such an attempt by Scott (1969), using reaction time, arithmetic, and two-flash discrimination as the tests of performance. The author states, "Preliminary results .... indicate ... relation to Stage 1-REM, 2 and $3+4$, respectively." Performance in the latter half of the night was also regarded as more like that of waking.

The final item of this brief review is a recent article by Seminara \& Shavelson (1969) which differs from the others in that the setting for the tests was an altitude chamber configured to represent an early lunar shelter. The Ss were confined in this for 5 days and had to make typical emergency responses to auditory warning signals presented when they were alert or asleep. Performance on sudden awakening was inferior in all three tests: (1) immediate response to the warning sound and then (2) setting a system of rotary switches, potentiometers, and valves, and (3) donning a pressure suit. Performance was worst within 3 min of a wakening, but $9 \mathrm{~min}$ after awakening it was still below normal.

From this review it seems clear that progressively greater impairment in monitoring the status of five meters, within $10 \mathrm{~min}$ of arousal from normal sleep at night, the performance of a number of tasks is less efficient than under usual conditions of alertness. Given agreement on this point, two unresolved questions remain for immediate consideration. The first concerns how much of the above difference may be due to the effect of time of day (or night) upon performance independent of the influence of sudden arousal. Only the study of Agnew, Webb, \& Williams avoids this problem, by arousing men from sleep in the afternoon. Perhaps it is significant that they found the effects of the sudden awakening were confined to the $60 \mathrm{sec}$ following waking. Five minutes later, the men were performing normally, whereas in other studies involving night awakenings, a residue of inefficiency remained for up to $10 \mathrm{~min}$. This could be due solely to tonic physiological levels being set for sleep rather than wakefulness and might not be present following sleep during the day.

The second question concerns the time of night at which people are awakened. If the depth of sleep varies through the night, we ought to expect time of awakening to have a bearing upon the subsequent level of performance. The present experiment was designed specifically to study this question.

\section{PROCEDURE}

The Ss were enlisted men of average intelligence, volunteers, and under 30 years of age. The tests were carried out at the service unit in which the men lived. They were aroused once only during the nights of the Tuesday, Wednesday, and Thursday of 5 successive weeks. On each occasion, they dressed informally and walked as quickly as possible from the dormitory to the testing room, a distance of about $50 \mathrm{ft}$. This took about $4 \mathrm{~min}$. On arrival at the testing room, they carried out three tasks which occupied about $11 \mathrm{~min}$, following which they returned to bed. As a control, they carried out the same routine of tasks at $1430 \mathrm{~h}$ on the Wednesday of each week, having been awake since the normal rising time of $0630 \mathrm{~h}$.

The Ss came in two groups, one of five and one of six members, for 5 weeks each.

They were aroused at one of four times: $0030,0130,0330$, and $0530 \mathrm{~h}$ on any given night. The first week served as a practice, and the scores were not included in the results.

The three tests used were: adding, reaction time, and a test of steadiness and coordination of motor control. Adding required the $S$ s to add columns of five two-digit numbers and write the answer at the foot of the column. The score was the number of these 


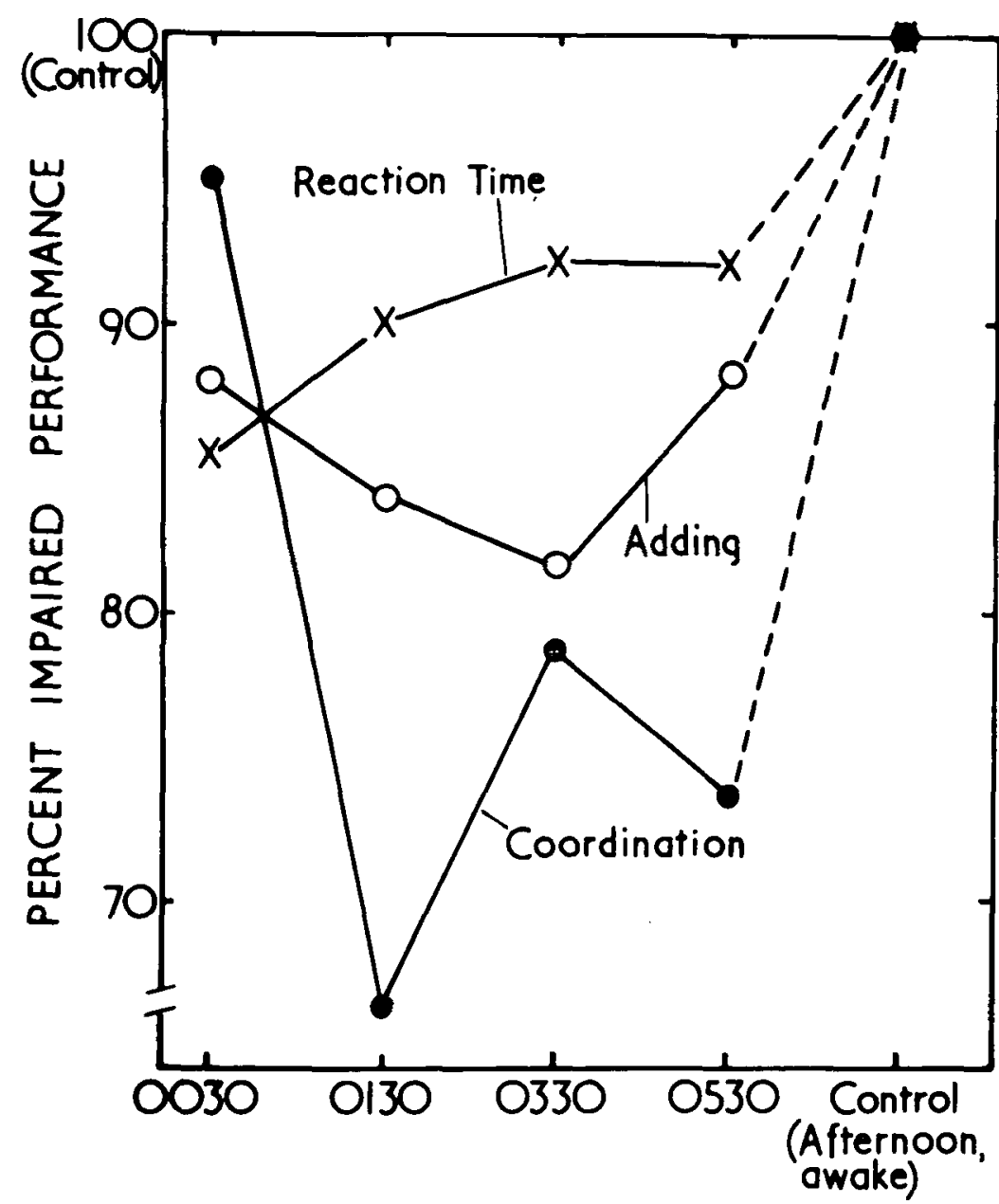

AROUSAL TIME (Hr)

Fig. 1. The degree to which performance is impaired following sudden awakening at different times of the night. For all three tests, reaction time, adding, and coordination impairment is expressed as a percentage of normal alerted performance during the day.

sums completed correctly in $3 \mathrm{~min}$. Reaction time required a simple keypressing response to a tone presented with warning. About 24 tones were presented at random intervals. For the third task, coordination, a $10 \times 10$ in. square tray was mounted at right angles on a short stick. The surface of the tray was of glass, surrounded by a raised wooden ledge. A metal ball, $3 / 4$ in. in diam, was placed on the glass as the $S$ held the tray horizontally on the handle. The task was to keep the ball at a point at the center of the tray. A count was made in arbitrary units of the time that the ball was maintained in this position. To do so, the tray had to be maintained absolutely level, a deviation causing the ball to roll away from the center point. Thus, while Ss had to compensate for any such deviation according to an acceleration law, the test was essentially one of the steadiness with which the tray was held in the horizontal plane. performance following sudden awakening was inferior to that under normal conditions in the afternoon, most of the differences being significant at better than the $5 \%$ level of probability, using Wilcoxon's nonparametric test (Siegel. 1956). Collapsing over the four times of testing, the effect of sudden awakening was examined as a function of the time since waking, which varied from 4 to 8 to $12 \mathrm{~min}$, according to whether the test occurred first, second, or third in the 11-min program which followed rising and getting to the testing room. No significant differences emerged with respect to any of the tests, implying that no pronounced recovery of function took place during the period $4.15 \mathrm{~min}$ following waking.

Figure 1 also shows the influence of time of waking upon the level of performance within 15 min of arousal. The trends vary with the nature of the task: reaction time was at its worst early in the night, adding and coordination were worse later, at 0330 and $0130 \mathrm{~h}$. When all possible pairs of testing times were compared, a number of the differences approached significance, but only those between 0030 and $0330 \mathrm{~h}$ in reaction time and 0030 and $0130 \mathrm{~h}$ in coordination were significant at better than the $5 \%$ level of probability. Nevertheless, the curve for reaction time appears almost the mirror image of that for adding, while that of coordination has features common to both.

\section{DISCUSSION}

The present experiment, since it incorporated tests involving a reasonably wide range of skills, suggests strongly that men's performance will be below normal for at least $15 \mathrm{~min}$ after being suddenly called to action from their normal night's sleep. This conclusion supports, in general, previous results in rather different settings, which suggests that the finding may have fairly general application.

Little has been added concerning the time course of the recovery of performance after wakening, except perhaps that in the present setting no evidence of swift recovery over a few minutes was seen.

The data on the influence of the time of sudden awakening are more interesting, although in some cases they fall tantalizingly short of conventional significance levels. Two factors might be expected to influence these results: One is the depth of sleep, which, if it be related to presence of EEG Stage 4 sleep or to sensory threshold during sleep (Rechtschaffen, Hauri, \& Zeitlin, 1966; Zung \& Wilson, 1961), might be expected to produce poor performance early in the night with a 
progressive improvement later on as sleep becomes shallower. The second factor is the circadian rhythm of physiological and behavioral activity, which usually reaches its lowest point rather later in the night, between the hours of 0300 and 0500 . Conceivably, these two influences could have interacted in the present experiments to produce an impression of no change in performance during the course of the night. In fact, what appears to have happened is that one test, the reaction time, responded as if to depth of sleep, while the other two, particulariy adding, responded as if to the circadian cycle. It is interesting to note that reaction time is a situation requiring relatively few quick discrete decisions. The other two tests affected later in the night required continuous application and concentration, though for only $3 \mathrm{~min}$. This dichotomy between intermittent and continuous work may prove useful in any further attempts to distinguish tonic circadian factors from phasic arousal ones in situations where men are suddenly called to action from sleep.

\section{REFERENCES}

A GNEW, H. W. WEBB, W. B., \& WILLIAMS, R. L. The effects of Stage 4 sleep deprivation. Electroencephalography \& Clinical Neurophysiology, 1964 . $17,68-70$.

HAR TMANN, B., \& LANGDON, D. E. Performance on sudden awakening. USAF School of Aerospace Medicine Report No. 62-17, 1961.

HARTMANN, B. \& LANGDON, D. E. A second study on performance upon sudden awakening. USAF School of Aerospace Medicine Report No, 5 AM-TR-65-61, 1965.

HARTMANN, B.. LANGDON, D. E., \& WILLIAMS, R. $L$. A third study on performance upon sudden awakening.
USAF School of Aerospace Medicine Report No. 5AM-TR-65-63, 1965.

JEANNARET $P$ T WEBB $W$. $B$. Strength of grip on arousal from full night's sleep. Perceptual \& Motor Skills, $1963,17,759-761$.

RECHTSHAFFEN, A., HAURI, P., \& ZEITLIN, M. Auditory awakening thresholds in REM and NREM sleep stages. Perceptual \& Motor Skills, 1966, 22. 927-941.

SCOTT, J. Performance after abrupt arousal from sleep: Comparison of a simple motor, a visual-perceptual and a cognitive task. Proceedings of $77 \mathrm{th}$ Annual Convention of the American Psychological Association, 1969.

SEMINARA, J. L., \& SHAVELSON, R. J. Effectiveness of space crew performance subsequent to sudden sleep arousal. Journal of Aerospace Medicine, 1969, 40, 723-727.

SIEGEL, S. Nonparametric statistics for the behavioral sciences. New York: McGraw-Hill, 1956.

ZUNG, W. K. W., \& WILSON, W. P. Response to auditory stimulation during sleep. Archives of General Psychiatry, $1961,4,548-552$. 